\title{
Avaliação da Lipase AK de Pseudomonas fluorescens imobilizada em suporte PHB na catálise da reação de transesterificação
}

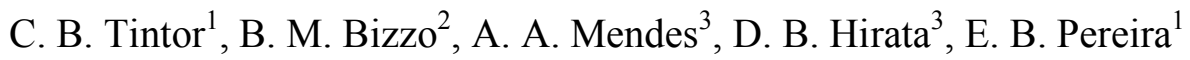 \\ ${ }^{1}$ Universidade Federal de Alfenas, Programa de Pós Graduação em Ciência e Engenharia Ambiental \\ ${ }^{2}$ Universidade Federal de Alfenas, Curso de Biotecnologia \\ ${ }^{3}$ Universidade Federal de Alfenas, Instituto de Química \\ E-mail para contato: ernandes.pereira@unifal-mg.edu.br
}

\begin{abstract}
RESUMO - As lipases atuam na hidrólise de triacilgliceróis, liberando ácidos graxos e glicerol. Em meio orgânico são enzimas capazes de catalisar reações de esterificação, interesterificação e transesterificação, sendo que seu uso somente é viável se associada à estabilização em suportes inertes. A eficiência de imobilização depende de fatores diversos como o suporte e tipo de imobilização. Na ocasião trabalhou-se com o suporte polihidroxibutirato (PHB) para imobilização da lipase de Pseudomonas fluorescens (Lipase AK). A atividade catalítica da lipase imobilizada por adsorção, foi de 413,76 U/g, utilizando um carregamento de $30 \mathrm{mg}$ de proteína durante a imobilização. A reação de transesterificação foi com óleo residual, conduzidas em shaker, usando $20 \mathrm{~g}$ do meio reacional, em proporção molar de 1:9 (óleo:etanol) e $2 \mathrm{~g}$ de derivado, à $45^{\circ} \mathrm{C}$, em diversos tempos (de zero a $96 \mathrm{~h}$ ). A formação de ésteres de etila foi acompanhada por cromatografia à gás e verificou que em $48 \mathrm{~h}$ atingiu $74 \%$ de rendimento.
\end{abstract}

\section{INTRODUÇÃO}

As lipases são enzimas classificadas como hidrolases tem a função de catalisar a hidrólise de gorduras e óleos vegetais com a subsequente liberação de ácidos graxos livres, diacilgliceróis, monoacilgliceróis e glicerol livre. Também podem atuar como catalisadores de reações de acidólise, aminólise, alcoólise (transesterificação), esterificação e interesterificação. Com o uso destes catalisadores enzimáticos, verifica-se algumas vantagens sobre os catalisadores clássicos, como a especificidade, a regiosseletividade e a enantiosseletividade (que permitem a catálise de reações com um número reduzido de subprodutos que demandam condições brandas de temperatura e pressão), a facilidade na remoção do catalisador do meio onde se encontra o produto e a possibilidade de reutilização do mesmo em vários ciclos reacionais, conforme Paques \& Macedo (2006); Leca et al. (2010). São enzimas comumente encontradas na natureza, podendo ser obtidas a partir de fontes animais, vegetais e microbianas.

De acodoc om Castro et al. (2004), inicialmente, as enzimas eram obtidas a partir de pâncreas de animais e usadas como auxiliar digestivo para consumo humano. Em função do baixo rendimento no processo fermentativo, as lipases microbianas foram consideradas dispendiosas, quando comparado ao custo de outras hidrolases com o mesmo fim. Entretanto, os avanços registrados na 


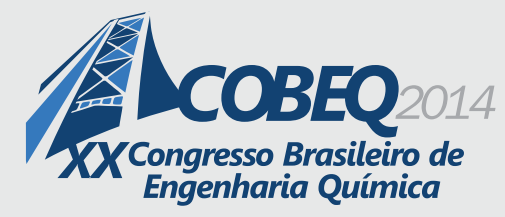

tecnologia do DNA têm permitido aos fabricantes de enzimas disponibilisar lipases microbianas com atividade bem elevada, a um custo mais acessíve.

Jaeger e Reetz (1998) especificam que as razões para o enorme potencial biotecnológico de lipases microbianas incluem os fatos de que elas são (1) estáveis em solventes orgânicos, (2) não necessitam de cofatores, (3) possuem uma grande especificidade de substrato e (4) exibem uma alta enantioseletividade.

Para ser competitivo o uso de enzimas, a sua reutilização é uma necessidade, e apesar de boas produtividades serem reportadas em exemplos da literatura empregando enzimas livres, os experimentos são conduzidos em regime de batelada de uso único, sem tentativas de recuperação da atividade enzimática, conforme Nielsen et al. (2008). Guisan (2006) define que a imobilização consiste no confinamento da enzima em um suporte sólido para posterior reutilização do biocatalisador, tornando o processo menos oneroso.

Yahya (1998) fez estudos comparativos que mostram diferenças acentuadas no desempenho de lipases imobilizadas nos vários suportes, e evidenciam que apesar das várias experiências reportadas na literatura, a imobilização ainda é um desafio complexo, uma vez que a extensão da imobilização depende da estrutura da enzima, método de imobilização, e do tipo de suporte. Em muitos casos, suportes que proporcionam uma elevada atividade e estabilidade da enzima apresentam sérias limitações de resistência mecânica e de queda de pressão, que os tornam inviáveis para a utilização em alguns tipos de reatores.

Para Lee et al. (2002); Shah et al. (2004) e Dors (2011), a imobilização é considerada como uma abordagem para melhorar o desempenho operacional de enzimas em processos industriais, especialmente para sistemas não aquosos. Várias abordagens têm sido utilizadas para a imobilização de lipases para a síntese de biodiesel, incluindo a adsorção, a encapsulação, imobilização covalente em um suporte, bem como a imobilização livre de suporte.

Desta forma, Knothe et al. (2006) e Dors (2011) descreveram que a vantagem principal do uso de lipases imobilizadas é a possibilidade de recuperação e reuso após um processo batelada e, desta forma, diluição do custo inicial da enzima. Além disso, o empacotamento de enzimas imobilizadas em colunas permite uma fácil implementação do processo contínuo. Deve ser levado em conta que a imobilização da enzima tem um efeito benéfico na estabilidade da enzima, em função das interações físicas e químicas entre o suporte e as moléculas da enzima. A imobilização também auxilia na dispersão homogênea da enzima no meio, o que é essencial para a condução de reações enzimáticas em meio não aquoso. As principais desvantagens deste processo são: alteração da conformação nativa da enzima, custo do suporte e possibilidade de perda de atividade durante o processo de imobilização.

A reação química utilizada nesse trabalho para a produção de biodiesel foi a de transesterificação, que consiste na quebra das cadeias longas dos óleos, para que possam ligar um álcool de cadeia curta, mediado pela presença de uma enzima como catalisador e produzindo ésteres, conforme descrito por Rodrigues (2009), que verificou, ainda que estes ésteres possuem características que se aproximam do diesel tradicional e solucionam os problemas encontrados para a 


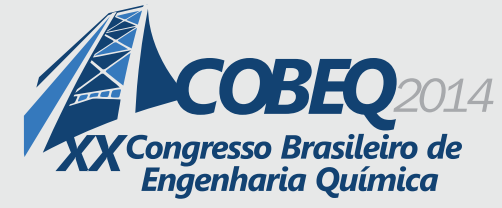

Engenharia Química
19 a 22 de outubro de 2014

Florianópolis/SC

aplicação de óleos vegetais como combustíveis. O uso de um excesso de álcool na reação foi oportuno para houvesse um deslocamento do ponto de equilíbrio, proporcionando um ganho significativo na produção de biodiesel ao final da batelada.

Quanto ao catalisador, o uso da lipase foi devido a sua eficácia na catálise de reações de transesterificação combinando as mais diversas matérias primas, sejam com o uso de diferentes óleos de origem vegetal ou animal; os brutos ou refinados e, até os óleos e gorduras residuais, bem como o uso de diversos alcoóis (como metanol, etanol, propanol, isopropanol, butanol ou isobutanol), conforme descreveu Dors (2011), em seu trabalho científico.

Por fim, destaca-se como propósito deste a avaliação do desempenho da Lipase AK imobilizada em suporte inerte do tipo Polihidroxibutirato (PHB), na catálise da reação de transesterificação entre resíduo gorduroso de fritura e etanol, estabelecidos diferentes tempos de reação, para uma condição fixa da razão molar óleo/etanol e condição de temperatura otimizada.

\section{MATERIAIS E MÉTODOS}

\subsubsection{Materiais}

A Lipase AK de Pseudomonas fluorescens utilizada é comercializada, pelo representante no Brasil da empresa Sigma Aldrich, assim como os suportes PHB, ambos encontrados na forma de pó. Já o resíduo gorduroso de fritura foi obtido no restaurante universitário da UNIFAL-MG. Como substrato padrão na caracterização da Lipase imobilizada e do sobrenadante, utilizou-se o azeite de oliva extra virgem, da marca Carbonell.

\subsubsection{Equipamentos}

Utilizou-se pH metro para o preparo da solução tampão, shaker orbital para imobilização, balança analítica para diferentes pesagens, bomba vácuo nas filtrações do suporte, shaker com controle de temperatura por banho Maria para reação de transesterificação, titulador automático com solução $\mathrm{NaOH}$ a $0,01756 \mathrm{M}$ para aferição da atividade hidrolítica, centrífuga para separação de subprodutos na reação de transesterificação, rotaevaporador composto por bomba á vácuo, rotor e banho Maria, dentre outros equipamentos básicos do laboratório. 
A pesquisa foi conduzida em duas etapas: a de imobilização da Lipase $\mathrm{AK}$ e da reação de transesterificação:
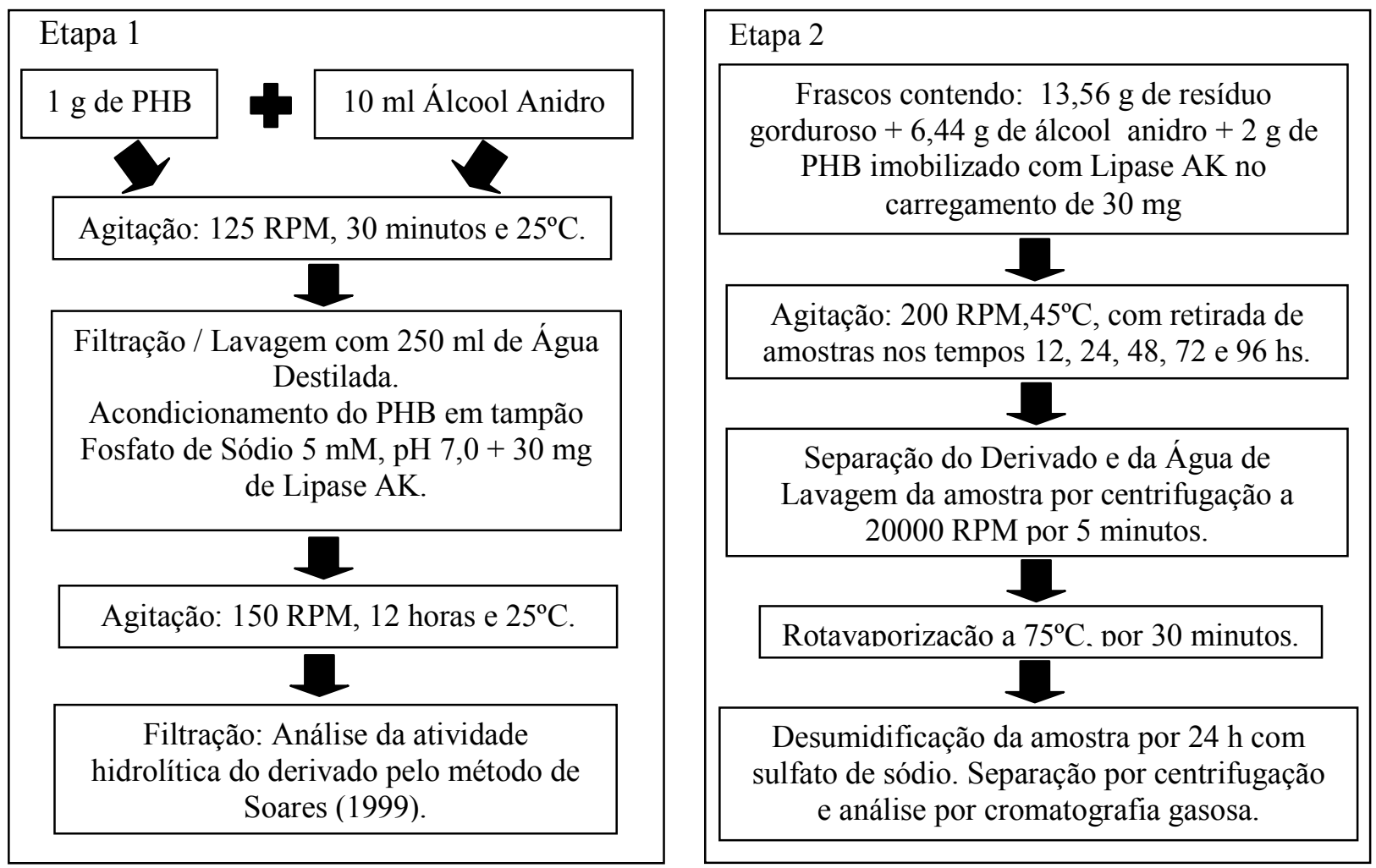

Figura 1: Fluxograma da metodologia de pesquisa empregada

\subsubsection{Métodos - Caracterização da Lipase}

Para a caracterização da Lipase $\mathrm{AK}$, algumas análises fizeram-se necessárias, sendo elas: avaliação dos fatores $\mathrm{pH}$ e temperatura ótimos de reação, além da determinação da melhor Atividade Hidrolítica de acordo com os diferentes carregamentos da Lipase AK imobilizada em PHB.

Em todas as análises, foi avaliada a atividade enzimática da lipase imobilizada, a qual era obtida pelo método de hidrólise do azeite de oliva, conforme metodologia modificada por Soares et al. (1999), onde verifica-se ácidos graxos liberados com titulação com solução de $\mathrm{NaOH}(\approx 0,02 \mathrm{M})$, utilizando fenolftaleína como indicador.

Para a determinação da atividade utilizou-se a equação 1:

$$
\begin{aligned}
& \mathrm{AH}=(\mathrm{Va}-\mathrm{Vb}) * 1000 * \mathrm{M}_{\mathrm{NaOH}} \\
& \left(\mathrm{m}_{\mathrm{e}}^{*} \mathrm{t}\right)
\end{aligned}
$$

Em que: 
Va: volume de $\mathrm{NaOH}$ gasto para titulação da amostra em $\mathrm{mL}$.

Vb: volume médio de $\mathrm{NaOH}$ gasto na titulação das soluções "branca" (sem enzima).

$\mathrm{M}_{\mathrm{NaOH}}$ : molaridade padronizada da solução de $\mathrm{NaOH}$ usada na titulação em mol/L.

$\mathrm{m}_{\mathrm{e}}$ : massa de derivado (PHB + enzima) utilizado em gramas.

t: tempo de reação em minutos.

A equação utiliza unidade de atividade (U), que é definida como a quantidade que libera $1 \mu \mathrm{mol}$ de ácido graxo por minuto de reação nas condições do ensaio. As atividades foram calculadas segundo a equação 1 e expressas em $\mu$ mol.min $\min ^{-1}(\mathrm{U})$.

Avaliação do pH ótimo de Reação: Afim de determinar a melhor performance catalítica da Lipase AK, foram desenvolvidas análises com determinação da atividade hidrolítica conforme metodologia proposta por Soares et al. (1999), no entanto com variação do pH da solução tampão usada. Neste ato, foram usadas duas soluções tampão distintas, o tampão fosfato e o tampão tris- $\mathrm{HCl}$, uma vez o tampão fosfato possui eficácia dentro da faixa de $\mathrm{pH}$ entre 5,0 e 8,0, enquanto que o tampão tris- $\mathrm{HCl}$ é eficiente para estabilidade tamponante em reações com $\mathrm{pH}$ acima de 8,5; ambos foram preparados com peso molar $0,1 \mathrm{M}$.

Assim, as avaliações de eficiência da enzima ocorreram entre pH 5,0 até 9,0, com escala gradativa de $\mathrm{pH}$ 0,5. Sendo que os demais fatores foram mantidos fixos (agitação de reação a 200 RPM, temperatura de reação em shaker com banho Maria de $37^{\circ} \mathrm{C}$, concentração de enzima no suporte de $5 \mathrm{mg}$ e alíquota de derivado imobilizado de $100 \mathrm{mg}$ ).

Avaliação da Temperatura ótima de Reação: Da mesma forma que a avaliação do melhor $\mathrm{pH}$, foram desenvolvidas análises com determinação da atividade hidrolítica conforme metodologia proposta por Soares et al. (1999), no entanto com variação da temperatura do banho maria. Assim, as avaliações de eficiência da enzima ocorreram nas temperaturas $30,37,40,45,50,55,60,65$ e $70{ }^{\circ} \mathrm{C}$ e os demais fatores mativeram-se fixos (solução tampão a $0,1 \mathrm{M}$ e pH 7,0, concentração de enzima no suporte de $5 \mathrm{mg}$ e alíquota de derivado imobilizado de $100 \mathrm{mg}$ ).

Avaliação do Carregamento ótimo no suporte: Consistiu em imobilizações de LPF em $1 \mathrm{~g}$ de suporte variando-se a carga enzimática oferecida de 2,5 a $40 \mathrm{mg}$ de proteína. $O$ tempo de imobilização foi de acordo com a metodologia apresentada na Figura 1, sendo esse tempo necessário para se atingir o equilíbrio da adsorção.

\subsubsection{Métodos - Reação de Transesterificação}

As reações de síntese de biodiesel a partir do resíduo gorduroso foram realizadas em recipientes fechados, utilizando agitação mecânica $(200 \mathrm{rpm})$, na temperatura de $45^{\circ} \mathrm{C}$ e razão molar fixa $1: 9$ resíduo gorduroso/ etanol. As reações foram incubadas com a lipase imobilizada em proporção $10 \%$ em relação à massa total dos reagentes e conduzidas por determinados períodos de tempo $(12,24,48$, 72 e 96h), com retirada dos recipientes amostrais para purificação e posterior dosagem dos ésteres etílicos formados. 


\subsubsection{Métodos - Determinação dos Ésteres Formados e Cálculo do Rendimento da Reação de Transesterificação}

Para a análise dos monoésteres de ácidos graxos foi empregado um cromatógrafo de fase gasosa. O rendimento das reações de síntese de biodiesel foi definido como o valor expresso da massa total obtida de ésteres de etila $\left(M_{t}\right)$ em relação a massa teórica esperada de ésteres de etila $\left(M_{e}\right) . M_{e}$ foi determinado a partir da massa de ácidos graxos presente na massa inicial do extrato de resíduo gorduroso $\left(\mathrm{M}_{0}\right)$, da massa molecular correspondente a cada ácido $\left(\mathrm{M}_{\mathrm{Ma}}\right)$ e do éster correspondente $\left(\mathrm{M}_{\mathrm{Me}}\right)$.

\section{RESULTADOS}

\subsubsection{Caracterização da Lipase}

Avaliação do pH ótimo de Reação: Conforme proposto por Soares et al. (1999), após a titulação das amostras obtidas, utizando-se solução de hidróxido de sódio padronizado em 0,01796 M, obtevese volumes determinados, os quais foram utilizados em substituição na equação (1) do item Va (volume de $\mathrm{NaOH}$ gasto para titulação da amostra em $\mathrm{mL}$ ). Da mesma forma, foram aferidos volumes determinados de amostras obtidas nas mesmas condições, porém sem a adição de enzima na imobilização. Estes volumes foram utilizados em substituição na equação (1) do item $\mathrm{Vb}$ (volume médio de $\mathrm{NaOH}$ gasto na titulação das soluções "branca" - sem adição de enzima). Pela Figura 2, nota-se que o melhor $\mathrm{pH}$, ou seja, uma maior atividade dessa enzima está em $\mathrm{pH} 8,0$.

Com os resultados obtidos foi possível desenvolver o gráfico abaixo (figura 2):

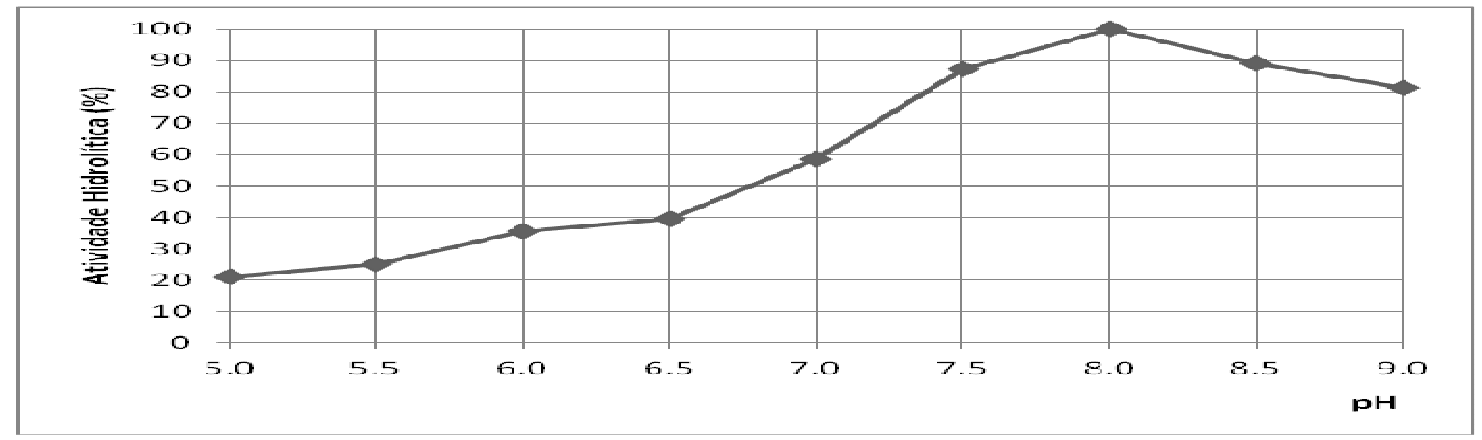

Figura 2: Determinação da atividade hidrolítica em função do pH

Avaliação da Temperatura ótima de Reação: A titulação com NaOH 0,01796 M. resultou em volumes determinados, os quais foram utilizados em substituição na equação (1) do item Va. Ainda, foram aferidos volumes determinados de amostras obtidas nas mesmas condições, porém sem a adição de enzima, os quais foram utilizados em substituição na mesma equação do item Vb. Observase que a melhor temperatura dessa enzima é a $40^{\circ} \mathrm{C}$. 


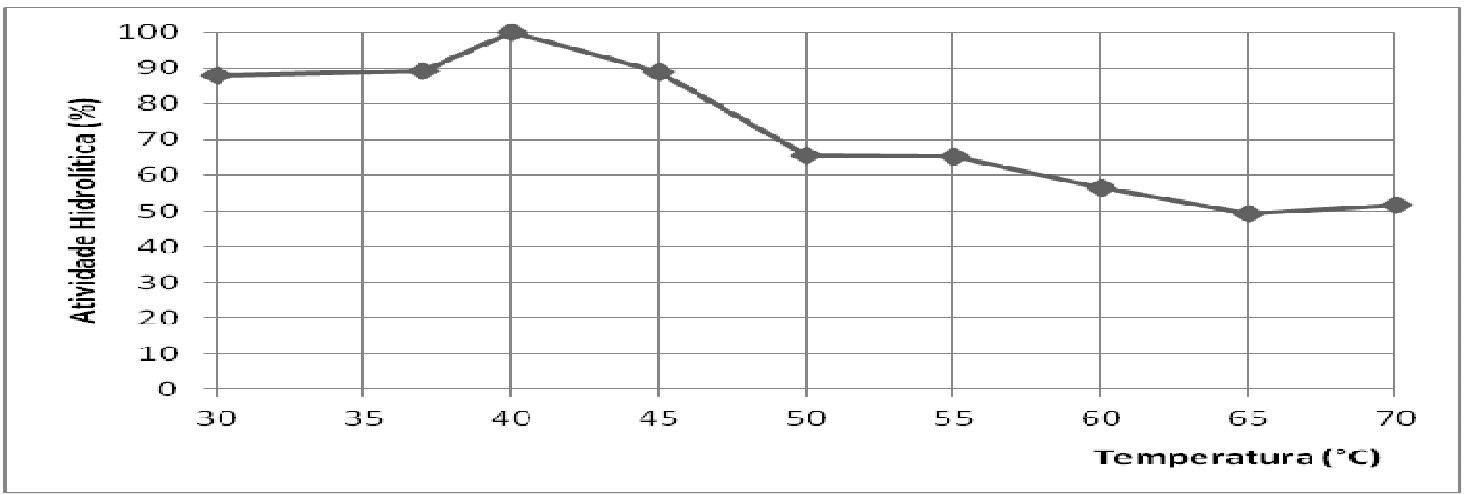

Figura 3: Determinação da atividade hidrolítica em função da temperatura

Avaliação do Carregamento ótimo no suporte: Dabaja et. al. (2013) e Bezerra et al. (2013), em seus trabalhos identificaram que a melhor atividade da lipase AK quanto aos diferentes carregamentos no suporte inerte PHB, é a do carregamento de $30 \mathrm{mg}$. Portanto, neste trabalho, avaliou-se a atividade do derivado com este carregamento imobilizado. Obteve-se uma atividade de 413,76 U/g. Os autores Dabaja et. al. (2013) e Bezerra et al. (2013), obtiveram uma atividade de $190,80 \mathrm{U} / \mathrm{g}$.

\subsubsection{Rendimento da Reação de Transesterificação}

Transcorridos os tempos determinados, as amostras foram coletadas e purificadas, ou seja, foram removidos: o derivado (PHB + Enzima), a glicerina, etanol e umidade. A análise por cromatografia gasosa apresentou os seguintes percentuais de ésteres, mostrados na Tabela 1.

Tabela 1 - Percentual de ésteres obtidos na reação de transesterificação, com variação nos tempos da reação

\begin{tabular}{|c|c|c|c|c|c|}
\hline Tempo & $12 \mathrm{~h}$ & $\mathbf{2 4} \mathrm{h}$ & $48 \mathrm{~h}$ & $\mathbf{7 2} \mathrm{h}$ & $96 \mathrm{~h}$ \\
\hline Percentual de Ester & $63,8 \%$ & $64,7 \%$ & $73,5 \%$ & $69,9 \%$ & $74,4 \%$ \\
\hline
\end{tabular}

\section{CONSIDERAÇÕES}

Das avaliações de temperatura e $\mathrm{pH}$, verificou-se que a metodologia usualmente aplicada, pode não ser a mais eficaz para reações de transesterificação com uso de enzima imobilizada por adsorção em suporte inerte e orgânico, como no caso do presente, que foi utilizado o polihidroxibutirato. Verificou-se, neste caso, que a otimização da reação se daria em $\mathrm{pH} 8,0$ e temperatura de $40^{\circ} \mathrm{C}$.

Ainda, no caso presente,optou-se conduzir a reação em pH 7,0 em função do tampão utilizado (solução tampão fosfato); trata-se de um tampão que apresenta pKa em 6,86 , ou seja, o ponto de melhor estabilidade de reação ocorre quando o tampão encontra-se estabilizado em $\mathrm{pH}$ aproximadamente 7,0. Além disso, conforme é possível verificar na figura 2, a reação em $\mathrm{pH} 7,0$ 


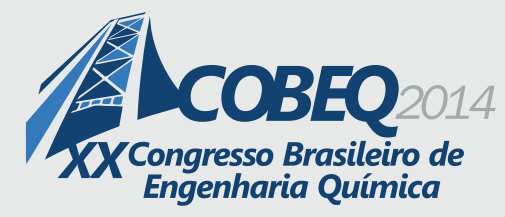

encontra-se em acessão logarítmica, sem possibilidade de qualquer estabilização ou saturação na reação.

Sobre o uso da temperatura de $45^{\circ} \mathrm{C}$ para a reação de transesterificação, conforme verifica-se na figura 3, é o ponto que há decréscimo logarítmico da atividade da enzima, porém sem possibilidade desta encontrar-se desnaturada. Além disso, quanto maior a temperatura, maior e a interação da enzima e suporte, tornado esta mais eficaz, no que diz respeito ao reuso.

A melhoria na atividade catalítica da enzima, conforme verificado no presente, em contraponto a atividade descrita pelos autores Dabaja et al. (2013) e Bezzera et al. (2013) é devido a tratar-se de uma enzima comercial, estando sujeita as condições no ato da fabricação. Além disso, fatores externos na condição da análise podem influenciar. No entanto, não descaracterizou o potencial de uso da enzima imobilizada, pelo contrário, reforçou, dado o aumento ser superior a $100 \%$.

Por fim, sobre a reação de transesterificação, verifica-se que o rendimento no tempo de 48 h é bastante similar ao tempo de $96 \mathrm{~h}$. Neste caso, novos testes são necessários, a fim de verificar a aplicabilidade de uma reação de transesterificação ocorrendo em menos que $48 \mathrm{~h}$, com a finalidade de produção comercial de biocombustível, onde o agente catalisador é uma enzima reutilizável.

Oportuno enfatizar que o presente trabalho compõe uma série de análises que estão sendo desenvolvidas, das quais objetivam a produção de uma energia de fonte alternativa, mais limpa, a qual da nova destinação de uso a produtos de descarte e com o uso de enzimas, que tornam o processo produtivo oportuno, devido a pouca quantidade de subprodutos produzidos; a baixa toxidade; a possibilidade de uso alternativo para os subprodutos e a chance do reuso, que é situação que começa a acenar para a produção contínua de biodiesel.

\section{REFERENCIAS}

BEZERRA, P. H. A.; HIRATA, D.B.; PEREIRA, E.B. Aplicação de lipase AK comercial de Pseudomonas fluorescens imobilizada em suporte PHB na síntese de bioaromas. Anais SIC 2013 UNIFAL, 2013. Acesso em 28 de abril de 2013, disponível em: http://www.unifalmg.edu.br/prppg/trabalhosSIC2013.

CASTRO, H. F. de; MENDES, A. A.; SANTOS, J. C. dos; AGUIAR, C. L. de. Modificação de óleos e Gorduras por Biotransformação. Química Nova, v. 27, p. 146-156, 2004.

DABAJA, M. Z.; HIRATA, D.B.; PEREIRA, E.B. Imobilização da lipase AK em PHB e sua aplicação na reação de transesterificação de óleo de açaí. Anais SIC 2013 UNIFAL, 2013. Acesso em 28 de abril de 2013, disponível em: http:/www.unifalmg.edu.br/prppg/trabalhosSIC2013.

DORS, G. Etanólise Enzimática do óleo de Palma Visando a Produção de Biodiesel em Sistema Contínuo. Dissertação (Doutorado Engenharia Química), Universidade Federal de Santa Catarina, 2011.

GUISAN, J. M. Immobilization of Enzymes and Cells. Totowa: Humana Press, 2006.

JAEGER, K.-E. e REETZ, M. T. Microbial lipases form versatile tools for biotechnology. Trends in Biotechnology. v. 16, p. 396-403, 1998. 
KNOTHE, G.; GERPEN, J. V.; KRAHL, J.; RAMOS, L. P. Manual de Biodiesel, 1a. ed., Edgard Blücher: (São Paulo), 2006.

LECA, M.; TCACENCO, L.; MICUTZ, M.; STAICU, T. Optimization of biodiesel production by transesterification of vegetable oils using lipases. Romanian Biotechnological Letters, v. 15, n. 5, 2010.

LEE, K.T.; FOGLIA, T.; CHANG K.S. Production of alkyl ester as biodiesel from fractionated lard and restaurant grease. Journal of the American Chemists' Society, v. 79, p. 191-195, 2002.

NIELSEN, P. M.; BRASK, J.; FJERBAEK, L. Enzymatic biodiesel production: Technical and economical considerations. European Journal of Lipid Science and Technology, v. 110, n. 8, p. 692-700, 2008.

PAQUES, F. W.; MACEDO, G. A. Lipases de látex vegetal: propriedades e aplicações industriais. Química Nova, v. 29, n. 1, p. 93-99, 2006.

RODRIGUES, R. C.; Síntese de biodiesel através de transesterificação enzimática de óleos vegetais catalisada por lipase imobilizada por ligação covalente multipontual. Dissertação (Doutor Engenharia Química), Universidade Federal do Rio Grande do Sul, 2009. Acesso em 14 de agosto de 2013, disponível em: http://www.lume.ufrgs.br/bitstream/handle/10183/15447/000681060.pdf?sequence=1.

SHAH, S.; SHARMA, S.; GUPTA, M. N. Biodiesel preparation by lipase-catalyzed transesterification of jatropha oil. Energy Fuel, v. 18, p. 154-159, 2004.

SOARES, C. M. F.; DE CASTRO, H. F.; DE MORAES, F. F.; ZANIN, G. M. Characterization and utilization of Candida rugosa lipase immobilized on controlled pore silica. Applied Biochemistry and Biotechnology, v. 77-9, p. 745-757, 1999.

YAHYA, A. R. M.; ANDERSON, W. A.; MOO-YOUNG, M. Ester synthesis in lipase-catalyzed reactions. Enzyme and Microbial Technology, v. 23, n. 7-8, p. 438-450, 1998. 